\title{
Comparative Study for the Prediction of Cavitating Flow inside a Square-Edged Orifice using Different Commercial CFD Software
}

\author{
Gong-Hee Lee ${ }^{1,2^{*}}$, and June-Ho Bae ${ }^{1}$ \\ ${ }^{1}$ Korea Institute of Nuclear Safety, Regulatory Assessment Department, 34142 Daejeon, Korea \\ ${ }^{2}$ University of Science and Technology, Nuclear and Radiation Safety Department, 34113 Daejeon, Korea
}

\begin{abstract}
Nuclear power plant operators conduct in-service testing (IST) to verify the safety functions of safety-related pumps and valves and to monitor the degree of vulnerability over time during reactor operation. The system to which the pump and valve to be tested are installed has various sizes of orifices for flow control and decompression. Rapid flow acceleration and accompanying pressure drop may cause cavitation inside the orifice, which may result in orifice degradation and structural damage. Though licensing applications supported by using Computational Fluid Dynamics (CFD) software are gradually increasing for IST-related problems, there is no CFD software which obtains a licensing from the domestic regulatory body until now. In this paper, to assess the prediction performance of different commercial CFD software for the analysis of cavitating flow inside a square-edged orifice, the simulation was conducted with ANSYS CFX and FLUENT R18.1. The results predicted were then compared with the measured data.
\end{abstract}

\section{Introduction}

The system to which the IST-related pump and valve to be tested are installed has various types and sizes of orifices for flow control and decompression. Rapid flow acceleration and accompanying pressure drop may cause cavitation inside the orifice, which may result in orifice degradation and structural damage. For example, cavitation and cavitation erosion of the letdown orifices in the chemical and volume control system for Diablo Canyon and Surry nuclear power plant could lead to fatigue failures of letdown line socket welds [1].

Since cavitating flows involve complex turbulent twophase flows, the accurate simulation of this flow by using the available CFD software is still a great challenge [2]. Though recently licensing applications supported by using CFD software are increasing for ISTrelated problems (including the orifice cavitation flow), there is no domestic regulatory guideline for the comprehensive evaluation of CFD software. Therefore, from the nuclear regulatory perspective, it is necessary to perform the systematic assessment and prepare the domestic regulatory guideline for checking whether valid CFD software and the numerical modeling is used for IST-related problems [2]. In this paper, to assess the prediction performance of different commercial CFD software for the analysis of cavitating flow inside a square-edged orifice, the simulation was conducted with ANSYS CFX and FLUENT R18.1.

\section{Analysis model}

Nurick [3] investigated cavitation characteristics inside various single orifices, made of lucite, stainless steel, and aluminum. Water was used as a working fluid. Fig. 1 shows a schematic diagram of test case.

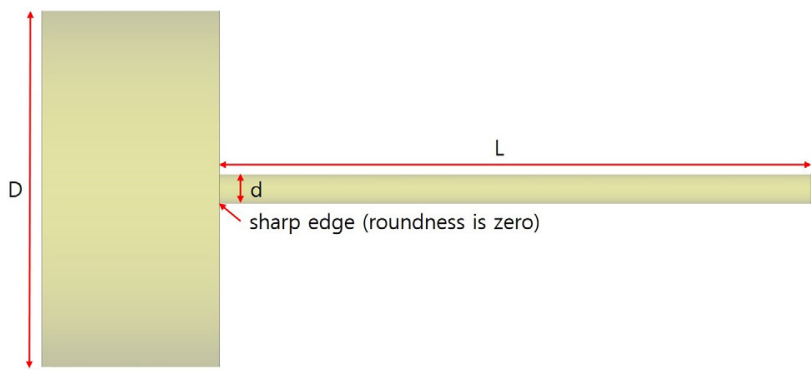

Fig. 1. Schematic diagram of test facility [2].

For this test case, tolerance of entrance sharpness was maintained to zero. Test case chosen in this study has smaller orifice diameter and larger ratio of upstream/orifice diameters, the cavitation flow inside this orifice may be more complex compared to the most referenced case. To the best of our knowledge, threedimensional CFD analysis for this test case may be the first attempt. Geometrical specification for test case are explained in Table 1.

Table 1. Geometrical specification for test case [2].

\begin{tabular}{|c|c|c|c|c|}
\hline $\begin{array}{c}\text { Upstream } \\
\text { diameter, } \\
\text { D (mm) }\end{array}$ & $\begin{array}{c}\text { Orifice } \\
\text { diameter, } \\
\text { d (mm) }\end{array}$ & $\begin{array}{c}\text { Diameter } \\
\text { ratio, } \\
\text { D/d }\end{array}$ & $\begin{array}{c}\text { Orifice } \\
\text { length, } \\
\text { L (mm) }\end{array}$ & L/d \\
\hline 38.1 & 3.175 & 12 & 63.5 & 20 \\
\hline
\end{tabular}

\footnotetext{
* Corresponding author: ghlee $@$,kins.re.kr
} 


\section{Numerical modeling}

The flow inside a square-edged orifice was assumed to be steady, incompressible, multiphase and turbulent flow. Numerical methods applied both in CFX and FLUENT were compared in Table 2.

Table 2. Comparison of the numerical methods.

\begin{tabular}{|c|c|c|c|}
\hline \multicolumn{2}{|c|}{ Items } & CFX & FLUENT \\
\hline $\begin{array}{c}\text { Discretization } \\
\text { accuracy (for } \\
\text { convection term) }\end{array}$ & $\begin{array}{c}\text { Momentum } \\
\text { equation }\end{array}$ & $\begin{array}{c}\text { High } \\
\text { resolution }\end{array}$ & $2^{\text {nd }}$ upwind \\
\cline { 2 - 4 } & $\begin{array}{c}\text { Turbulence } \\
\text { equation }\end{array}$ & $\begin{array}{c}\text { High } \\
\text { resolution }\end{array}$ & $2^{\text {nd }}$ upwind \\
\hline \multicolumn{2}{|c|}{ Interphase Transfer Model } & Mixture & Mixture \\
\hline \multicolumn{2}{|r|}{ Cavitation model } & $\begin{array}{c}\text { Rayleigh- } \\
\text { Plesset }\end{array}$ & $\begin{array}{c}\text { Zwart- } \\
\text { Gerber- } \\
\text { Belamri }\end{array}$ \\
\hline \multicolumn{2}{|c|}{ Turbulence model } & SST k- $\omega$ & SST k- $\omega$ \\
\hline \multicolumn{2}{|c|}{ Near-wall region } & $\begin{array}{c}\text { Automatic } \\
\text { wall } \\
\text { treatment }\end{array}$ & - \\
\hline \multicolumn{2}{|c|}{ Convergence criteria } & $10^{-6}$ & $10^{-6}$ \\
\hline
\end{tabular}

\subsection{Turbulence model}

Shear Stress Transport (SST) k- $\omega$ turbulence model, which is one of Reynolds-averaged-Navier-Stokes (RANS)-based two-equation turbulence models, was used to simulate cavitation flow inside a square-edged orifice. According to previous study [2], SST k- $\omega$ model showed the improved prediction performance to the standard $\mathrm{k}-\omega$ model in the orifice internal flow where flow impingement and reattachment, and re-circulation flow may exist.

\subsection{Grid system}

To obtain accurate prediction results in cavitation analysis using CFD software, it is essential to consider the use of a proper grid topology, especially at locations where cavitation may occur [4]. In this study, unstructured hexahedral grid system generated by ICEM-CFD, a grid generation tool, was used for calculating cavitation flow inside a square-edged orifice. The total number of grids used in the calculation was about $2 \times 10^{6}$. As shown in Fig. 2, to properly predict cavitation flow, dense grid distribution near the wall and the orifice entrance region were applied.

\subsection{Boundary condition}

Inlet condition was the specified constant upstream pressure in the range of between $P_{\text {in }}=300 \mathrm{kPa}$ and 10 $\mathrm{MPa}$. Constant turbulent kinetic energy and turbulent dissipation rate was applied. Volume fraction for water liquid was assumed to be 1 . Static pressure of $95 \mathrm{kPa}$ was specified as an outlet-boundary condition. No-slip condition was applied at the solid wall [2].

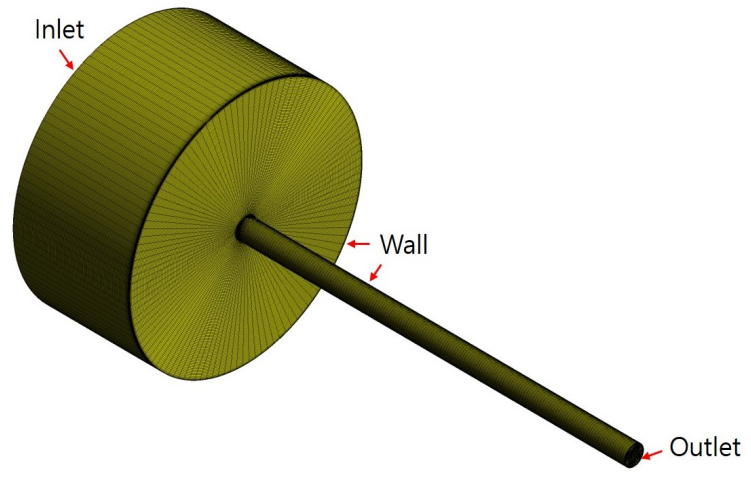

Fig. 2. Grid system [2].

\section{Result and discussion}

The flow inside For cavitation flow inside an orifice, variation of discharge coefficients $\mathrm{C}_{d}$ depending on the cavitation number $\sigma$ is one of primary interest. These variables can be defined as follows [3];

$$
\begin{gathered}
\sigma=\frac{P_{\text {in }}-P_{v}}{P_{\text {in }}-P_{b}} \\
\mathrm{C}_{d}=\frac{\dot{m}_{\text {actual }}}{\dot{m}_{\text {ideal }}}=\mathrm{C}_{c} \sqrt{\sigma}
\end{gathered}
$$

where $P_{b}=95,400 \mathrm{~Pa}$ is outlet pressure, $P_{v}=3,540 \mathrm{~Pa}$ is vapor pressure, and $\mathrm{C}_{c}=0.62$ is contraction coefficient [3]. Table 3 shows the selected inlet pressure and the corresponding cavitation number.

Table 3. Inlet pressure and the corresponding cavitation number.

\begin{tabular}{|c|c|c|c|}
\hline $\begin{array}{c}\text { Inlet pressure } \\
\boldsymbol{P}_{\text {in }} \mathbf{( k P a )}\end{array}$ & $\begin{array}{c}\text { Cavitation } \\
\text { number } \boldsymbol{\sigma}\end{array}$ & $\begin{array}{c}\text { Inlet pressure } \\
\boldsymbol{P}_{\text {in }}(\mathbf{k P a})\end{array}$ & $\begin{array}{c}\text { Cavitation } \\
\text { number } \boldsymbol{\sigma}\end{array}$ \\
\hline 200 & 1.87105 & 450 & 1.25763 \\
\hline 250 & 1.59006 & 500 & 1.22583 \\
\hline 300 & 1.44615 & 600 & 1.18111 \\
\hline 310 & 1.42540 & 750 & 1.13963 \\
\hline 320 & 1.40649 & 900 & 1.11361 \\
\hline 330 & 1.38919 & 3,000 & 1.03148 \\
\hline 350 & 1.35867 & 5,000 & 1.01865 \\
\hline
\end{tabular}

Fig. 3 shows the comparisons of the predicted discharge coefficients $\mathrm{C}_{d}$ and Nurick's correlation, defined in equation (2). The predicted $\mathrm{C}_{d}$ magnitudes with ANSYS CFX showed good agreement with Nurick's correlation in the cavitation regime. On the other hand, ANSYS FLUENT under-estimated $\mathrm{C}_{d}$ magnitudes in comparison with Nurick's correlation in the cavitation regime.

This work was supported by the Nuclear Safety Research Program through the Korea Foundation Of Nuclear Safety (KOFONS) using the financial resource granted by the Nuclear Safety and Security Commission (NSSC) of the Republic of Korea (No. 1805007). 


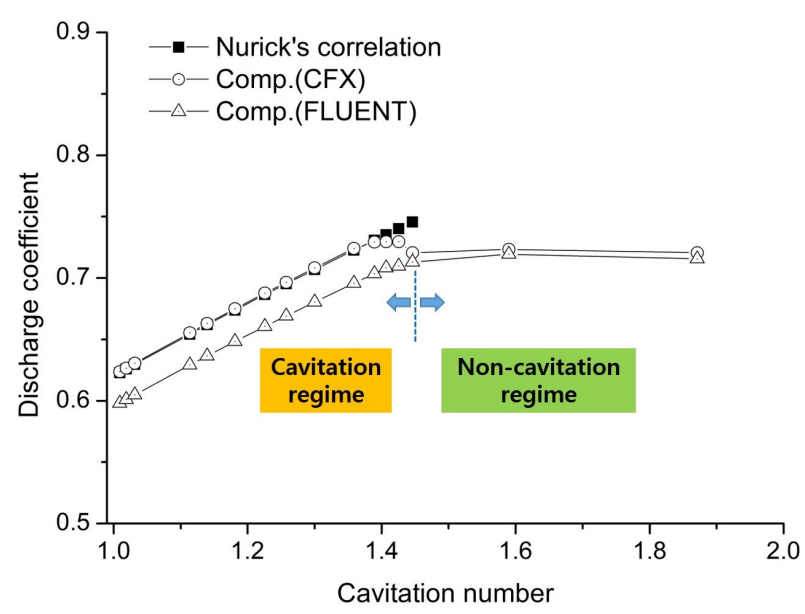

Fig. 3. Comparison of the predicted discharge coefficients and Nurick's correlation.

\section{References}

1. US NRC, Information Notice, No. 98-45 (1998)

2. G.H. Lee, J.H. Bae, 15th Asian International Conference on Fluid Machinery, AICFM15-091 (2019)

3. W.H. Nurick, J. Fluid Eng. 98, (1976)

4. G.H. Lee, J.H. Bae, Proc. KSCFE Spring Conf., (2019) 